\title{
Configurações
}

Revista de sociologia

\section{O fenómeno thug e a prevenção da violência na cidade da Praia na perspetiva da polícia cabo- verdiana}

The Cape Verdean police reality in the fight against and prevention of urban violence and the "thug" phenomenon in the city of Praia Le phénomène "thug" et la prévention de la violence dans la ville de Praia dans la perspective de la police capverdienne

Jassica B. M. Tavares

\section{(2) OpenEdition}

\section{Journals}

Electronic version

URL: http://journals.openedition.org/configuracoes/5218

DOI: $10.4000 /$ configuracoes.5218

ISSN: 2182-7419

Publisher

Centro de Investigação em Ciências Sociais

Printed version

Number of pages: 96-112

ISSN: 1646-5075

\section{Electronic reference}

Jassica B. M. Tavares, « O fenómeno thug e a prevenção da violência na cidade da Praia na perspetiva da polícia cabo-verdiana », Configurações [Online], 21 | 2018, Online since 30 June 2018, connection on 08 January 2020. URL : http://journals.openedition.org/configuracoes/5218; DOI : 10.4000/ configuracoes.5218 
Tavares, Jassica B. M. - 0 fenómeno do thug e a prevenção da violência na cidade da Praia na perspetiva da polícica cabo-verdiana. Configurações, vol. 21, 2018, pp. 96-112.

\section{0 fenómeno thug e a prevenção da violência na cidade da Praia na perspetiva da polícia cabo-verdiana}

JASSICA B. M. TAVARES*

ISMAI

\section{Resumo:}

Este artigo pretende dar a conhecer a perspetiva da polícia cabo-verdiana relativamente ao combate e à prevenção do fenómeno thug e da violência urbana na cidade da Praia, partindo dos dados empíricos obtidos de uma investigação qualitativa, realizada no âmbito de uma dissertação de mestrado. A realidade cabo-verdiana sobre a violência urbana tem chamado a atenção pela sua dimensão e expressão associada ao fenómeno thug, caracterizado por grupos de jovens envolvidos em violência urbana coletiva. Este fenómeno tem vindo a aumentar sentimentos de insegurança na população praiense e, como consequência, o aumento de respostas mais repressivas por parte dos agentes de controlo formal. Os resultados obtidos chamam a atenção para a importância de adoção de novas estratégias para resolução destas problemáticas, como a necessidade de uma reforma do sistema de justiça juvenil e alterações na atuação da polícia, que se quer mais eficaz e preventiva.

Palavras-chave: polícia, violência urbana, fenómeno thug, cidade da Praia, jovens.

\footnotetext{
Abstract

The Cape Verdean police reality in the fight against and prevention of urban violence and the "thug" phenomenon in the city of Praia

This article intends to show the perspective of the Cape Verdean police regarding the combat and prevention of the "thug" phenomenon and urban violence in the city of Praia, based on empirical data obtained from a qualitative research carried out on the police of all the squadrons of the city of Praia, at the end of 2015 under the scope of a master's dissertation. The Cape Verdean reality about these social scourges has drawn attention to the fact that we are systematically being surprised by acts of violence in their most diverse forms and dimensions. These phenomena are

* Licenciada e Mestre em Criminologia (ISMAI - Portugal.

E-mail: sicatavares@live.com.pt
} 
associated with young people, acting in organised groups and calling themselves "thugs", coming from the most diverse areas and social classes in the city. The results obtained call attention to the importance of adopting new strategies to solve these problems, such as the need for the reform of the juvenile justice system and the issues inherent to the police in order to act effectively and efficiently with regard to urban violence and the thug phenomenon.

Keywords: Police, urban violence, thug phenomenon, city of Praia, young people.

\section{Résumé}

Le phénomène "thug" et la prévention de la violence dans la ville de Praia dans la perspective de la police capverdienne

Cet article vise à montrer le point de vue de la police capverdienne sur la lutte et la prévention du phénomène thug et de la violence urbaine dans la ville de Praia, à partir des données empiriques obtenues dans une enquête qualitative menée dans le cadre d'une thèse de master.

La réalité capverdienne face à la violence urbaine a attiré l'attention en raison de sa dimension et de l'expression associée au phénomène thug, caractérisé par des groupes de jeunes impliqués dans la violence urbaine collective. Ce phénomène a augmenté les sentiments d'insécurité dans la population de la ville, et par conséquent, les réponses plus répressives des agents de contrôle formel.

Les résultats obtenus attirent l'attention sur l'importance d'adopter de nouvelles stratégies pour résoudre ces problèmes, par exemple le besoin de réformer le système de justice pour mineurs et les changements dans l'action de la police qui se veut plus efficace et préventive.

Mots-clés: Police, violence urbaine, phénomène thug, ville de Praia, jeunes.

\section{Introdução}

A violência urbana em Cabo Verde é um fenómeno que tem assolado, especificamente, a cidade da Praia, capital do país. A população praiense tem vindo a reclamar por medidas sérias e adequadas para lidar com este problema. Visto como uma preocupação de política pública e criminal, existem, porém, grandes inconformidades sociais e institucionais quanto ao seu efetivo combate e prevenção.

Cabo Verde é hoje um país com altas taxas de violência e com sérios problemas sociais e económicos, expressos nas grandes desigualdades sociais que aí se encontram. O aumento da violência urbana tem sido acompanhado do aumento dos sentimentos de insegurança, que tem levado à necessidade de novas formas de combate repressivas implementadas pelo governo local (Bordonaro, 
2010, p. 108). Aliás, os desafios de Cabo Verde têm sido o combate e a prevenção da criminalidade nas suas mais diferentes formas e dimensões.

A violência urbana em Cabo Verde tem sido retratada como um fenómeno eminentemente juvenil, uma vez que os seus protagonistas são, na sua grande maioria, jovens, com idades compreendidas entre os 14 e os 24 anos de idade, designados de thugs $^{1}$. Esta é uma expressão utilizada para referir grupos organizados de jovens, especialistas em violência urbana coletiva.

Importa, assim, perceber qual o papel da polícia enquanto órgão formal de controlo do crime. Que responsabilidades tem a polícia cabo-verdiana no combate e na prevenção da violência urbana juvenil? Que representações a polícia cabo-verdiana tem sobre a violência urbana que assola o país?

$\mathrm{Na}$ tentativa de responder a estas questões, apresentam-se alguns dos dados de um estudo qualitativo realizado no âmbito de uma dissertação de mestrado intitulada "O fenómeno thug e a violência urbana na cidade da Praia (Cabo Verde): A perspetiva da polícia da cabo-verdiana".

\section{Violência urbana na cidade da Praia}

$\mathrm{Na}$ cidade da Praia é evidente o sentimento de insegurança por parte dos que lá vivem e dos que lá vão. Muito se tem falado, nos fóruns públicos, debates políticos ou conversas de café, sobre a violência vivenciada. O discurso prevalente é de que nada tem estado a ser feito para colmatar a presente situação. $\mathrm{O}$ que não contraria os sentimentos de insegurança da população cabo-verdiana, os dados estatísticos oficiais ou os estudos realizados (INE, 2010; Lima, 2010, 2012; Bordonaro, 2012; Cardoso, 2012).

Os dados estatísticos de Cabo Verde apresentam um aumento significativo dos registos criminais, tanto ao nível nacional (leia-se, nas diferentes ilhas), como ao nível local. A ilha de Santiago surge como a região mais violenta de Cabo Verde, fruto do facto da cidade da Praia, capital do país, apresentar dos maiores registos criminais a nível nacional (INE, 2010; DNPN, 2011, 2014).

Os dados estatísticos têm sido corroborados pelos estudos realizados por vários autores, como Lima (2010; 2012), Bordonaro (2012) e Cardoso (2012) que têm referenciado o fenómeno da violência urbana no contexto da cidade da Praia como um fenómeno juvenil. Se a violência urbana tem sido descrita como um fenómeno eminentemente juvenil, que põe em causa o bem-estar social (Duarte e Carvalho, 2013), em Cabo Verde a sua expressão não pode ser dissociada do facto de ser um país muito jovem e com muitos problemas sociais graves associados a esta faixa etária. Desemprego jovem, falta de escolaridade

1 Vem do inglês e significa, rufia, bandido, assassino. 
(que tem afetado mais os jovens de classes baixa), adolescentes e jovens desafiliados, uso problemático de substâncias psicotrópicas, são apenas alguns desses problemas. Quase trinta e dois por cento da população tem idade inferior aos 15 anos, 64,8\% tem idades compreendidas entre os 15 e 64 anos e apenas $3,64 \%$ mais 65 anos (INE, 2011). Os bairros suburbanos da cidade da Praia são aqueles que apresentam uma taxa maior de população juvenil com os problemas sociais identificados (Lima, 2010; Cardoso e Roque, 2009).

Face aos problemas identificados, foram levadas a cabo algumas transformações ao nível social e político. Segundo Bordonaro (2010) a Polícia Militar tem atuado no combate e na prevenção da violência urbana, o que levou à criação de corpos de intervenção e investigação especializados. Face ao aumento das ocorrências de violência na cidade da Praia, o aumento das medidas repressivas e punitivas passou a ser uma realidade visível. Ora, a polícia, enquanto uma instituição do Estado e um órgão formal de controlo do crime, "tem por funções defender a legalidade democrática, prevenir a criminalidade e garantir a segurança interna, a tranquilidade pública e o exercício dos direitos dos cidadãos" (ver artigo 244으 n. 1 da Constituição da República de Cabo Verde e art. $1^{\circ}$ da Lei de Segurança Interna 16/VII/2007). Segundo a Lei n ${ }^{\circ} 30 / V I I / 2008$, a Esquadra de Investigação e Combate Criminal (EICC) é constituída por duas unidades, a BAC (Brigada anticrime) e a BIC (Brigada de investigação criminal), que têm como finalidade a intervenção imediata, com medidas sérias de repressão e prevenção criminais, alargando assim a competência investigatória da Polícia Nacional. Estas brigadas foram criadas em 2013 para fazer face às altas taxas de criminalidade na cidade da Praia. Embora estas medidas se tornem mais visíveis em 2013, o combate à criminalidade sempre foi uma preocupação do Governo Cabo-verdiano. Entre 2006 a 2011 o Plano Estratégico de Segurança Interna já passava por "promover a segurança das pessoas e bens e afirmar a autoridade do Estado” em relação a estas matérias. (MAI, 2011).

\section{Enquadramento metodológico}

Estudar a realidade policial em Cabo Verde e ouvir as vozes dos seus atores contribui para diminuir alguma da invisibilidade académica e científica que as tem envolvido. Neste sentido, este estudo assume um carácter exploratório e em certa medida inovador nesta área. O estudo realizado teve como objetivo central perceber a perspetiva da polícia da cidade da Praia sobre a violência urbana. Foi realizada uma investigação que fez cruzar duas principais técnicas de recolha de dados: inquéritos por questionários e entrevistas semiestruturadas. Estes instrumentos foram administrados aos polícias de todas as esquadras de polícia da cidade da Praia. O levantamento dos dados decorreu nos meses de novembro e dezembro de 2015. 
Foi feito um primeiro levantamento de todas as esquadras de polícia da cidade da Praia e do seu número de efetivos. Existem cinco (5) esquadras de polícia e um total de cento e cinquenta e seis (156) efetivos de polícia (ver Quadro 1).

Quadro 1: Esquadras de polícia da cidade da Praia e número de efetivos.

\begin{tabular}{lc}
\hline Esquadras de Polícia da Cidade da Praia & Números de Efetivos \\
\hline Esquadra de Polícia de Achada de São Filipe & 25 \\
Esquadra de Investigação e Combate Criminal (EICC) & 54 \\
Esquadra de Polícia de Achada de Eugénio Lima & 21 \\
Esquadra de Polícia de Fazenda & 31 \\
Esquadra de Polícia de Palmarejo & 25 \\
\hline
\end{tabular}

Fonte: Levantamento feito durante o trabalho de campo no ano de 2015

Os inquéritos por questionários foram distribuídos pelas cinco esquadras de polícia da cidade da Praia ao número total de efetivos (N=156); responderam setenta e um (n=71) polícias (ver Quadro 2).

Quadro 2: Esquadras de polícia: número de efetivos e número de respondentes.

\begin{tabular}{lcc}
\hline \multicolumn{1}{c}{ Esquadras de Polícia da Cidade da Praia } & $\begin{array}{c}\text { Número de } \\
\text { Efetivos (N) }\end{array}$ & $\begin{array}{c}\text { Número de } \\
\text { Respondentes (n) }\end{array}$ \\
\hline $\begin{array}{l}\text { Esquadra de Polícia de Achada de São Filipe } \\
\text { Esquadra de Investigação e Combate }\end{array}$ & 25 & 11 \\
Criminal & 54 & 19 \\
Esquadra de Polícia Achada Eugénio Lima & 21 & 09 \\
Esquadra de Polícia Fazenda & 31 & 15 \\
Esquadra de Polícia Palmarejo & 25 & 17 \\
Total & 156 & 71 \\
\hline
\end{tabular}

Fonte: Inquérito por questionários realizados durante o trabalho de campo no ano de 2015

Os questionários foram deixados em cada esquadra de polícia, com uma prévia explicação e simulação de como os preencher, sendo posteriormente feita 
a sua recolha. Os dados do questionário foram analisados estatisticamente, através do programa estatístico SPSS.

Relativamente às entrevistas, traçou-se como objetivo 15 entrevistas (três por cada esquadra), mas foram realizadas apenas seis entrevistas. Três na Esquadra de Polícia de Achada de São Filipe e outras três na Esquadra de Polícia do Palmarejo. A obtenção das entrevistas foi bastante difícil e o principal motivo subjacente foi o facto de os polícias não mostrarem interesse em colaborar, dizendo estar ocupados ou justificando desconhecer a autorização para o estudo. Houve também problemas comunicacionais, o que fez com que se fosse perdendo tempo e oportunidade de realização de entrevistas. As entrevistas foram gravadas em áudio e realizadas nas próprias esquadras de polícia. Após a sua transcrição literal, as narrativas foram codificadas e analisadas de acordo com uma grelha dividida em duas (2) grandes categorias.

Categoria 1: Expressão da violência urbana na cidade da Praia. Aqui foram analisados os protagonistas da violência, os tipos de crimes, as zonas críticas, a evolução dos crimes ao longo do tempo, a origem da violência e a classificação dos crimes cometidos.

Categoria 2: Combate a violência urbana, nesta categoria as dimensões de análise foram as taxas de reincidência, a repressão/prevenção, os meios humanos/meios materiais, de combate, os pontos positivos/negativos e as propostas e soluções.

No que concerne aos respondentes dos questionários, foram na sua maioria do sexo masculino (84,5\%). O corpo policial é bastante jovem: 41,2\% com idade compreendida entre os 20 - 30 anos. Isto verifica-se também no tempo de serviço, sendo que $30,0 \%$ dos polícias contavam entre zero a quatro anos de serviços. São na sua maioria agentes $(78,9 \%)$ e pertencentes a Esquadra de Polícia do Palmarejo (68,0\%).

Quadro 3: Caraterização dos participantes respondentes do questionário

\begin{tabular}{ll}
\hline Respondentes do questionário & Média \\
\hline Sexo & Masculino (84,5\%) \\
Idade & $20-30$ anos $(41,2 \%)$ \\
Tempo de serviço & $0-4(30,0 \%)$ \\
Categoria profissional & Agentes $(78,9 \%)$ \\
Local de trabalho & Esquadra de Polícia do Palmarejo $(68,0 \%)$ \\
\hline
\end{tabular}

Fonte: Trabalho de campo realizados nos finais do ano de 2015. 
Os entrevistados são agentes pertencentes às Esquadras de polícia de Palmarejo e de Achada de São Filipe, sendo um do sexo feminino e dois do sexo masculino, respetivamente.

Quadro 4: Caraterização dos entrevistados

\begin{tabular}{lll}
\hline \multicolumn{1}{c}{ Entrevistados } & \multicolumn{1}{c}{$\begin{array}{c}\text { Categoria } \\
\text { profissional }\end{array}$} & Sexo \\
\hline Esquadra de Polícia de Palmarejo & Agentes & $1-$ feminino \\
& & $2-$ masculino \\
Esquadra de Polícia de Achada de São Filipe & Agentes & $1-$ feminino \\
& & 2 -masculino \\
\hline
\end{tabular}

Fonte: Trabalho de campo realizados nos finais do ano de 2015.

Os princípios éticos foram assegurados através da solicitação do consentimento informado, o pedido para a gravação das entrevistas e a garantia do caráter voluntário da participação, bem como da reserva do anonimato e da confidencialidade de todos os dados recolhidos. De forma a garantir a privacidade e o anonimato dos participantes, os seus nomes foram substituídos por nomes fictícios.

Quadro 5: Identificação e caraterização dos entrevistados

\begin{tabular}{l} 
E 1: Maria, agente da Polícia Nacional, nacionalidade cabo-verdiana, residente na \\
cidade da Praia, trabalha na Esquadra da Polícia do Palmarejo, 6 anos de serviço. \\
\hline E 2: João, agente da Polícia Nacional, nacionalidade cabo-verdiano, residente na \\
cidade da Praia, trabalha na Esquadra da Polícia do Palmarejo, 8 anos de serviço. \\
\hline E 3: Pedro, agente da Polícia Nacional, nacionalidade cabo-verdiano, residente na \\
cidade da Praia, trabalha na Esquadra da Polícia do Palmarejo, 12 anos de serviço. \\
\hline E 4: Joana, agente da Polícia Nacional, nacionalidade cabo-verdiana, residente na \\
cidade da Praia, trabalha na Esquadra da Polícia de Achada de São Filipe, 10 anos de \\
serviço. \\
E 5: Miguel, agente da Polícia Nacional, nacionalidade cabo-verdiano, residente na \\
cidade da Praia, trabalha na Esquadra da Polícia de Achada de São Filipe, 3 anos de \\
serviço. \\
E 6: Manuel, agente da Polícia Nacional, nacionalidade cabo-verdiano, residente na \\
cidade da Praia, trabalha na Esquadra da Polícia de Achada de São Filipe, 15 anos de \\
serviços.
\end{tabular}

Fonte: Trabalho de campo realizados nos finais do ano de 2015. 


\section{Violência urbana: origem, protagonistas e discursos}

Os grupos organizados de jovens responsáveis pela violência urbana juvenil coletiva era já uma realidade vivida na Cidade da Praia. Segundo Lima (2010), nos anos de 1980 e 1990 já existiam os "piratinhas” e os "netinhos da vovó", Contudo, a partir do ano de 2008, uma nova onda de violência urbana começa a fazer sentir-se na cidade da Praia. Desta vez os seus protagonistas, também jovens, passam a denominar-se de thugs. Segundo Bordonaro (2012, p. 108), os thugs são jovens associados a gangues que surgiram recentemente (na década de 2000) e rapidamente se espalharam nas cidades da Praia e do Mindelo (estando a alargar-se a outras zonas urbanas), redefinindo as modalidades da 'criminalidade juvenil' (Lima, 2012; Bordonaro, 2006; Cardoso, 2012).

O entendimento de que a violência urbana na cidade da Praia vem aumentando nos últimos tempos tem estado muito associado ao aparecimento e consolidação deste grupo. Para 90,1\% dos inquiridos os atos de violência urbana têm estado a aumentar, perceção complementada pelos seus discursos e pelos dados estatísticos:

"Sim...aumentou sim, antigamente eu ia trabalhar e não havia nenhuma queixa, reclamação nem nada e agora é difícil fazer um turno sem 2 ou 3 queixas (...)” (E 1, Maria).

"Bastante... a violência urbana é muito (...)” (E 2, João).

“(...) está a aumentar...está preocupante (...)” (E 3, Pedro).

Quando analisamos os registos criminais de 1996 a 2014, esse aumento é evidente (ver Gráfico 1). Estes dados tornam-se mais preocupantes quando, analisando um estudo realizado pelo MAI $(2011,2012)$, se percebe que a população cabo-verdiana deprecia a atuação da polícia e acredita na impunidade dos agressores e na falta de vontade dos polícias e de outros órgãos responsáveis em por cobro à situação. Para 42,2\% dos inquiridos "não vale a pena" fazer queixa ou procurar as entidades competentes em caso de violência.

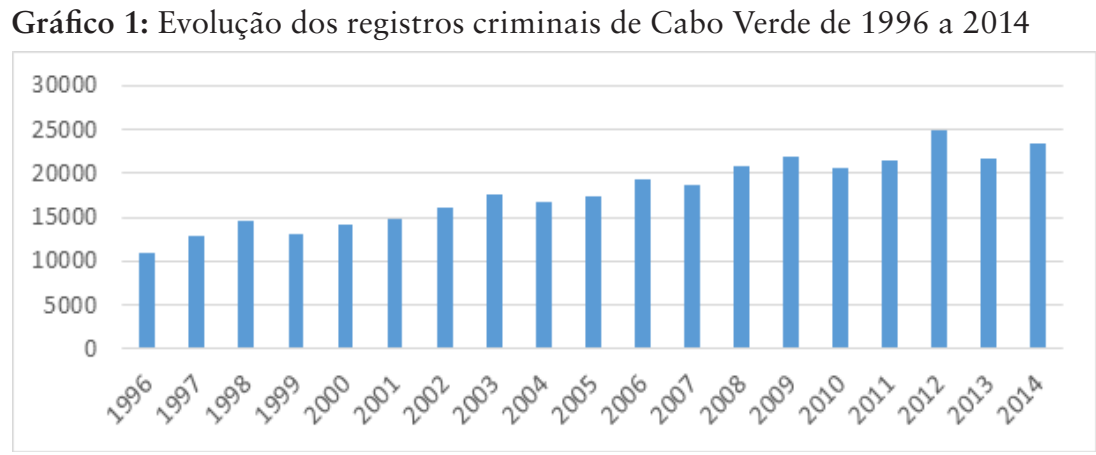


Quanto à tipologia dos crimes referenciados, são os crimes contra as pessoas e os crimes contra a propriedade, designado de kassu body ${ }^{2}$, que mais se destacam. Assaltos à mão armada, roubos e furtos a residências e automóveis e homicídios são as tipologias mais identificadas. Ao longo do tempo estes tipos de crime foram se alterando, tendo maior expressão crimes mais violentos no decorrer do tempo. A partir dos anos de 2000, a violência urbana juvenil torna-se mais visível e preocupante. Desde então houve um aumento significativo dos registos criminais, com o agravamento da tipologia e complexidade dos crimes, como é o caso de crime de homicídio, tanto por encomenda como por ajuste de contas. Oitenta e cinco e meio por cento dos inquiridos caracterizam este facto como muito grave:

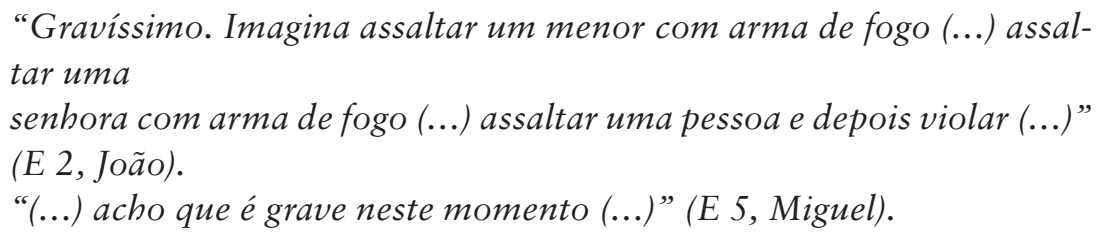

Os atos de violência urbana juvenil na cidade da Praia, na ótica da polícia, estão enquadrados em épocas específicas do ano, por diferentes motivações e para fins diversos. As épocas do ano em que ocorrem mais atos de violência urbana são, segundo os inquiridos, as épocas festivas e as épocas de verão, $88,7 \%$ e $35,2 \%$, respetivamente. As atuações ocorrem em diversas zonas da cidade (centros, zonas comerciais e zonas habitacionais). Segundo a DNPN (2012), podemos classificar a cidade da Praia em zonas urbanas sensíveis e zonas urbanas normalizadas. Esta ideia é partilhada por Bordonaro (2010, p. 10) e Cardoso (2012, p. 25), que apontam os espaços públicos e de diversão noturna, zonas e/ou bairros rivais, zonas periféricas, grandes centros urbanos enquanto espaços preferenciais de atuação destes grupos, grupos estes caraterizados como sendo geograficamente dispersos e horizontalmente organizados. Para os inquiridos, as motivações apontadas para o surgimento destes grupos são: o uso problemático de substâncias psicotrópicas $(91,5 \%)$, a falta de emprego e/ou ocupação $(52,1 \%)$ e problemas familiares $(35,2 \%)$. Não obstante, outras motivações também foram apresentadas, como ser visto como uma forma de rendimento, pela a existência de subculturas delinquentes e pelos contextos de pobreza em que vivem. Estas motivações vão ao encontro dos estudos que têm sido feitos sobre esta realidade. Bordonaro (2012), Lima (2010) e Cardoso (2012) têm indicado os problemas sociais e económicos como causas do aumento da violência urbana juvenil na cidade da Praia. Entre estes problemas destacam a pobreza, as drogas, o álcool, a prostituição, o desemprego, o abandono escolar, pouco ou nenhuma vigilância comunitária ou familiar, 
exclusão social, etc. Ainda assim, por quanto a pobreza nunca tenha sido referenciada como causa direta ou única da violência, os autores alertam para a não 'criminalização da pobreza'.

Quanto à finalidade desta violência, para $81,7 \%$ dos inquiridos ela assume a forma de violência gratuita, não utilitarista e negativa. Para 69\% tem como principal finalidade a obtenção de rendimento e para 40,8\% ela é uma expressão e forma de masculinidade. Para a grande maioria, a principal finalidade tem sido para a obtenção de rendimento, bem como expressão e forma de masculinidade.

\section{Combate a violência urbana}

No que concerne ao combate à violência urbana na cidade da Praia, encontramos grandes contradições entre os depoimentos e sentimentos da sociedade civil e os discursos dos órgãos e instituições responsáveis, como é o caso da polícia. A comunicação social fala-nos do descontentamento e da insegurança sentidas pelas populações. Os órgãos e instituições responsáveis apresentam um discurso de que o combate e a prevenção contra a violência têm sido prioridade e de um trabalho necessário e constante já existente.

Do estudo realizado podemos concluir, quer pelos inquéritos quer pelas entrevistas, que a polícia considera o seu trabalho como sendo positivo $(79,7 \%$ dos respondentes), embora $42 \%$ dos respondentes apontem a falta de meios tanto materiais como humanos (dos menos significativos para os mais significativos) para combater esta forma de violência. Para João "a própria polícia não tem muitos meios de combater a violência (...). Agora o que conta é colocar no terreno a estratégia policial porque está muito má” (E 2). Ideia apresentada também por Pedro e por Maria, que dizem, respetivamente:

"Não temos meios materiais suficientes (...) sempre temos falta deagentes" (E 3). "Meios humanos e matérias, tudo isso precisamos, viaturas velhas, precisamos de novas, computadores, impressoras quando há uma avaria desses aparelhos temos que esperar até que seja comprada uma outra nova e isso acaba dificultando no registo das queixas.” (E 1).

Questionados relativamente à falta de policiamento, 85,1\% discorda que essa seja a causa do aumento das taxas de violência na cidade da Praia, culpabilizando as novas formas de dinâmicas familiares, sociais e comunitárias, que parece estarem a perder espaço e força no controlo informal do crime.

Apresentam também como fator de aumento constante da violência urbana as taxas de reincidência, e reconhecem que é muito difícil os protagonistas afastarem-se da prática criminal, por não haver apoio a todos os 
níveis, nomeadamente familiar e social. Esta perceção é corroborada pelos entrevistados:

"Tem sim (...) depois de cumprirem a pena de prisão ...não vai para a cadeia fica como se estivesse livre então todos eles continuam a fazer as mesmas coisas a cometer os mesmos crimes." (E 3, Pedro).

"É um facto verídico, porque são poucas as pessoas que saem daquela vida...

suspendem temporariamente... começam novamente com as atividades” (E 4, Joana).

"Em principios sim, porque é assim, há alguns que vão detidos e depois de 3 meses, 6 meses, depois de serem libertados, alguns "melhoram" ... $e$ a outros que depois que saem (das prisões) passam uns tempos "sossegados" e depois estão a planear outros crimes e voltam a cometer" (E 6, Manuel).

Além de sublinharem a importância dos processos de aprendizagem do crime, no seio dos pequenos grupos (família, amigos vizinhos...), destacam que muitos dos reincidentes são aqueles que não têm uma ocupação social e construtiva. A proteção que em alguns casos recebem da família é referenciada, também, como uma causa do aumento das taxas de reincidência. Para Maria, “(...) às vezes há mães que apoiam, são coisas que nós dentro da policia constatamos (...)" (E 1).

A proteção da família aparece muitas vezes ligada ao facto de, em muitos casos, o fruto da violência urbana estar relacionada com o sustento da família e também da proteção dos seus familiares de abusos de poder da própria polícia.

\section{A atuação das polícias da cidade da Praia}

Nos termos do artigo $2^{\circ}$ da Orgânica da Polícia Nacional, o corpo policial de Cabo Verde sofreu uma profunda reorganização. Em 2005 a POP (Polícia de Ordem Pública) foi modificada, criando assim a PN (Polícia Nacional), que integra a ordem pública, guarda-fiscal, polícia marítima, trânsito, estrangeiros e fronteiras, e a polícia florestal numa única unidade. O ano de 2006 (em particular) foi referenciado por Bordonaro (2012, p. 11) como ano de grandes mudanças no sector da segurança interna, no que respeita às medidas de prevenção e combate a criminalidade.

No presente estudo, os participantes reconhecem que o trabalho da polícia tem sido positivo, admitindo que o fenómeno da violência urbana na cidade da Praia, por ser um problema juvenil, é também uma questão de cariz social, comunitária, familiar, etc. 
A forma de atuação da polícia tem sido vista como repressiva, o que Lima (2010) e Bordonaro (2010) veem referenciando nos seus trabalhos, caraterizando os agentes de causadores de incivilidades, pelo uso extremo da força e do poder e pelas sucessivas violações de direitos humanos (Bordonaro, 2010). No entanto, tal é contrário ao discurso policial.

“(...) mas acredito que todos os dias temos trabalhado na prevenção, prevenir criminalidade proteger o cidadão e os seus direitos” (E 1, Maria).

"Nós somos mais na base da prevenção (...)” (E 3, Pedro).

“(...) nós a polícia não trabalhamos só na repressão, mas na prevenção também e isto acontece quando a polícia está numa zona.” (E 6, Manuel).

À luz da Lei Orgânica da Polícia Nacional, Cabo Verde tem uma polícia de natureza preventiva, que se traduz no discurso da polícia. A Lei 78/VII/2010 de Política Criminal, no seu artigo $3^{\circ}$, refere que tem por objetivos prevenir e reprimir a criminalidade e reparar os danos dela resultantes, tomando em consideração as necessidades concretas de defesa dos bens jurídicos e das vítimas, bem como a reintegração do agente do crime na vida comunitária.

No entanto, as práticas referenciadas no estudo são meramente repressoras, sendo que os agentes reconhecem a necessidade da utilização da força para a resolução de alguns problemas pontuais, como por exemplo a confissão de um suspeito e até mesmo como forma de impor ordem e respeito:

“(...) não aquela lei está mais para os bandidos, para fazeres uma atuação tens de ter muito cuidado com os direitos humanos, imagina agora uma pessoa diz foi ela que me roubou, trazemos aqui [esquadra] para tentarmos convencê-lo a confessar, se os policia darem duas palmatórias ele vai na televisão fazer queixa e as pessoas ficam a dizer que foi abuso (policial) e isto e aquele, mas as pessoas não sabem que no fundo foi através daquela palmatória que recebeu que foi capaz de confessar (...)" (E 1, Maria).

“(...) podes dar a qualquer pessoa uma chicotada ao decorrer de uma interrogação e depois és penalizado” (E 5, Miguel).

A polícia tem sido algumas vezes questionada e criticada, principalmente pela existência de violência e abusos policiais. Não faltam depoimentos nas televisões, rádios e até em conversas diárias que não indiciem que certos atos cometidos pela polícia não estejam dentro do quadro legal. O último relatório das Nações Unidas (JEI, 2015) chama a atenção para alguns casos de 
uso excessivo da força e de abusos por parte da polícia. Em contrapartida, o Governo de Cabo Verde reconhece, segundo MAI (2011), a existência de órgãos e de profissionais e especialistas competentes na área do combate e prevenção da criminalidade e da violência.

Para Valente (2015) a forma correta como a polícia trabalha é tendo em atenção sempre os valores da justiça, da legalidade democrática, da prevenção da criminalidade, do garantir a segurança interna e a tranquilidade pública, e o exercício dos direitos dos cidadãos. A polícia tem como função a resolução de problemas que outras instituições (família, escola, igreja, etc.) não têm capacidade para resolver, nunca pondo em causa, contudo, a liberdade pessoal.

A polícia, para além de falta de meios, humanos e materiais, reconhece alguns fracassos em algumas estratégias de atuação, bem como outras preocupações e alternativas. Desta feita, apresentam as seguintes "Propostas \& Soluções":

"Eu acho que em relação aos thugs devem ser tomadas mais seriedades na aplicação da lei. (...) Não basta a aplicação de leis severas, mas sim trabalhar com as comunidades, ter a polícia e as outras instituições mais próximas das pessoas para ver se conseguimos atenuar esta situação que está emergente em alguns bairros." (E4, Joana).

"(...) em Palmarejo ${ }^{3}$ se tivéssemos agentes civis no terreno, infiltrar civis nos terrenos nas zonas de mais assaltos vai diminuir são coisas que já aconteceu diminuiu" (E 2, João).

"É mais social do que investigativo, da parte da investigação é conhecer o foco, os motivos da parte social como já nos conhecemos é fácil juntarmos para trabalharmos para a comunidade. (...) Eu propunha um trabalho em conjunto um djunta mó ${ }^{4}$ entre a família, instituição públicas, todos os intervenientes da comunidade, associações comunitárias para todos nós em conjunto trabalharmos porque nós já conhecemos estes jovens já conhecemos as suas famílias" (E 4, Joana).

Também lhes foi questionado sobre as políticas públicas existentes e se estas vêm sendo eficazes no combate ao crime. $\mathrm{O}$ que se percebe nas várias respostas é uma certa confusão entre políticas públicas, políticos e vontade política, como aqui podemos descrever.

3 Palmarejo, é um bairro da cidade da Praia. É um bairro recente onde vivem pessoas de classe média e classe média alta e fica próxima de um bairro problemático.

4 Djunta Mó, é uma expressão crioula, que significa todos a trabalhar, trabalho em conjunto, responsabilidade de todos, etc.. 
"Não...política mesmo nos nossos políticos cada faz as coisas pelo seu próprio interesse não estão preocupados em combater este flagelo, esta violência urbana porque eles têm os seus próprios interesses em primeiro lugar" (E 5, Miguel).

O fenómeno da violência urbana tem sido merecedor de atenção e preocupação de todos; efetivamente, muito se tem falado deste fenómeno enquanto um flagelo, uma bola de neve que atinge a cidade da Praia. Os próprios polícias reconhecem incapacidades de atuação, porque ela não é meramente um problema administrativo.

Os sucessivos governos de Cabo Verde têm mostrado alguma preocupação relativamente ao combate a violência urbana. O anterior Governo de Cabo Verde apresentou uma proposta de um novo modelo de justiça restaurativa juvenil, aplicável a ofensores dos 16 aos 21 anos em crimes mais leves (RTC, 2015), bem como outros programas de prevenção da violência e o combate a outros tipos de criminalidade, em concreto, a criminalidade organizada transnacional. No atual programa do Governo, o combate à criminalidade está no centro das atenções sob o signo da Tolerância zero à criminalidade, com maior destaque para os centros urbanos, atuando na prevenção e combate à proliferação de armas, bem como para a pequena criminalidade e criminalidade organizada.

A imagem que se quer mostrar, da polícia organizada, dotada de meios e capacidades de trabalho e com vontade de bem servir Cabo Verde foi desvalorizada pelos discursos de não haver comunicação e articulação entre os dirigentes políticos e administrativo e a classe profissional que diariamente está no terreno.

Os agentes policiais queixam-se das diversas situações a que estão sujeitos enquanto profissionais: como lidar quando as preocupações profissionais passam a ser problemas pessoais e até familiares, como viver sob ameaça de delinquentes e/ou criminosos, o desrespeito por parte da população e dos suspeitos, a pouca articulação entre a força policial e a força judicial, os riscos que correm em pleno exercício das suas funções que acaba por ser da sua total responsabilidade, receio das precárias condições de trabalho local (nas esquadras) e a sua relação com a (im)produtividade, entre outras.

A polícia cabo-verdiana vive hoje novos desafios face à modernização das vivências locais. A sua eficiência enquanto órgão formal de controlo do crime poderá ser útil no âmbito das suas funções da prevenção da criminalidade e da manutenção da ordem. Para que a polícia seja sinónimo de paz, tranquilidade e respeito mútuo, tem de se envolver todos os seus protagonistas, seja no quadro legal e formal da sua ação, seja no quadro social e informal, que integra toda a sociedade. 


\section{Conclusão}

Existem poucos estudos e produção científica e académica sobre a polícia cabo-verdiana que traga as vozes dos seus agentes para o centro. A polícia, enquanto um órgão formal de controlo de crime que mais perto está na sociedade, tem as suas responsabilidades e funções no que respeita à garantia da aplicabilidade de lei e da proteção dos cidadãos.

O estudo aponta para o aumento da violência urbana nos últimos dez anos em Cabo Verde, com destaque para a cidade da Praia, onde também tem sido evidente o agravamento na tipologia dos crimes praticados. Este aumento da violência é também visto enquanto um problema eminentemente juvenil, por ser praticado por jovens dos 14 aos 24 anos; daí ser referenciado enquanto violência urbana juvenil. Por este motivo, os polícias acreditam que o fenómeno da violência urbana juvenil necessita de uma intervenção social, comunitária e familiar e não apenas legal.

Apesar desta opinião, os discursos da polícia cabo-verdiana não deixam de legitimar o aumento de políticas e práticas mais repressivas e justificar o uso da força como forma de resolução de problemas. O que pode confirmar a tese de existência de abuso policial e de poder, que tem sido disseminada e denunciada pelos meios de comunicação social. Com isto podemos compreender que, apesar de os agentes se considerarem, no discurso, uma polícia de cariz preventivo, quando falam sobre as práticas, estas conduzem-nos para lógicas mais repressivas e reativas.

O combate à violência urbana na cidade da Praia parece ser posto em causa devido à escassez de meios humanos e materiais, e a limitações legislativas que se prendem com a perceção de que a lei beneficia mais os criminosos do que a própria polícia. Esta perceção parece estar ligada com uma outra. O estudo verificou que os polícias não acreditam nos políticos. Parece haver uma espécie de desvalorização e desacreditação quanto à vontade política no combate e prevenção da violência urbana. O discurso veiculado é de que os políticos não pensam no bem-estar da população, mas sim nos seus interesses pessoais. Uma problemática bem aprofundada e denunciada por Lima (2010, 2012).

Como resposta às altas taxas de violência e à ineficácia da atuação policial atual, objeto de grande crítica social e mediática, vislumbra-se como sendo necessário adotar novas medidas preventivas e de combate à violência, podendo as soluções passar, eventualmente, pela justiça restaurativa, a polícia de proximidade e/ou novas estratégias de atuação policial. 


\section{Referências bibliográficas}

BORDONARO, Lorenzo (2006), "Semântica da Violência Juvenil e repressão policial em Cabo Verde", Revista Direito e Cidadania, (30), 169-190.

BORDONARO, Lorenzo (2012), "Masculinidade, violência e espeço público: notas etnográficas sobre o Bairro Brasil da Praia (Cabo Verde)”, In Vera Duarte e Manuela Ivone Cunha (org.), (2014), Violência e delinquências juvenis femininas: género e (in) visibilidades, Famalicão, Húmus editora, 101-136.

CARDOSO, Kátia (2012), “Thugs e violências: mitos, riscos e omissões”, In José Manuel Pureza, Sílvia Roque e Kátia Cardoso (org.) (2012), Jovens trajetórias de violências. Os casos de Bissau e da Praia, Coimbra, Almedina, 19-52.

CARDOSO, Kátia; ROQUE, Ślvia (2009), “Jovens marginalização e violência”, P@X - Boletim do Núcleo de Estudos para a Paz, 13, (1), 1, disponível em

http://www.ces.uc.pt/nucleos/nep/media/PAX-13-pt-dez.pdf.

CARVAlHO, Maria João; DUARTE, Vera (2013), "Crianças, jovens e a cidade: riscos, violência e delinquência em Portugal”, Latitude, 7 (2), 133-166, disponível em file://C:/Users/ a025914/Downloads/1292-4457-1-PB.pdf.

DUARTE, Vera (2015), "Delinquência (s) no feminino: construção de um mosaico conceptual”, In Vera Duarte, Manuel Simas Santos, Olga Cruz e Helena Grangeia (2015), Delinquência juvenil: explicações e implicações organização, Maia, ISMAI (UICCC), 73-87.

FERERA, Jose, Manuel, et al. (1995), "Desvio e controlo social”, In Sociologia, Lisboa, The Mc Graw-Hill, 429-451.

LIMA, Redy, (2010), Thugs: vitimas elou agentes da violência, Instituto Superior das Ciências Jurídicas e Sociais, Praia, Cabo Verde.

LIMA, Redy, (2012), "Delinquência juvenil coletiva na Cidade da Praia: uma abordagem diacrónica”, In José Manuel Pureza, Sílvia Roque e Kátia Cardoso (org.) (2012), Jovens trajetórias de violências. Os casos de Bissau e da Praia, Coimbra, Almedina, 57-81.

VALENTE, Manuel, Guedes, (2014), Teoria geral de direito, (4 edição), Coimbra, Almedina.

VALENTE, Manuel, Guedes, (coord.) (2015), Ciências policiais e política criminal: Justiça e segurança: um discurso de liberdade democrática, Lisboa, Rei dos livros.

\section{Outra bibliografia}

CONSTITUIÇÃO DA RÉPUBLICA DE CABO VERDE, (2013), (4ª Edição), Praia, Assembleia Nacional.

INE (2010), Crimes contra pessoas e propriedades - 1996 a 2009, Cabo Verde.

INE (2011), Evolução do População residente segundo os censos de 1990 - 2010, Cabo Verde.

Lei da Segurança Interna, lei n $16 / \mathrm{VII} / 2007$ de 10 de setembro, Ministério da administração interna, Cabo Verde.

Lei de política criminal, lei no 78/VII/2010 de 30 de agosto, Ministério da administração interna, Cabo Verde.

Lei orgânica de polícia nacional, decreto, lei n³9/2007 de 12 de novembro, Ministério da administração interna, Cabo Verde.

MAI (2011), Estudo sobre a relação da organização dos espaços urbanos e a violência urbana em Cabo Verde, Cabo Verde.

MAI (2012), Estudo de seguimentos sobre a violência e criminalidade na Praia 2013, Cabo Verde.

Portaria n 38/2010 de 18 de outubro, Criação do BIC/BAC, lei nº 30/VII/2008, de 21 de julho, Ministério da administração interna, Cabo Verde. 
Programa do Governo da IX Legislatura (2016), disponível de https://rive.google.com/ file/d/0B8xPd2aD0.

Jornal expresso das ilhas (2015), Violência policial e lentidão da justiça são problemas em Cabo Verde - EUA, disponível em http://www.expressodasilhas.sapo.cv/sociedade/ item/48329-violencia-policial-e-lentidao-da-justica-sao-problemas-em-cabo-verde-eua.

Rádio e televisão de Cabo Verde, (2015), Governo vai levar ao Parlamento proposta de novo modelo de justiça juvenil, disponível em http://www.rtc.cv/tcv/index. php?paginas=13\&id_cod=45180. 